\title{
Electronic Money in the National Payment System: regional aspect
}

\author{
Natalia Kunitsyna \\ North-Caucasus Federal University, \\ Institute of Economics and Management \\ Chair of Finance and Credit department \\ Stavropol, Russia \\ natkun2004@mail.ru
}

\author{
Ekaterina Dyudikova \\ North-Caucasus Federal University, \\ Institute of Economics and Management \\ PhD student of Finance and Credit department \\ Stavropol, Russia \\ dudikova.e@gmail.com
}

\begin{abstract}
Electronic money is a high-tech segment of money circulation and one of the evolutionary stages of the payment system. The studies of the technological profile of electronic money genesis, which includes eight stages of its evolution, reveal the final formation of the technical-andtechnological concept and the need for the reinforcement of the financial content of electronic money in the legislation delegating some functions in the payment and settlement systems to new technologies. The functioning of the centralized electronic money systems and decentralized cryptocurrency systems helped to reveal their advantages and disadvantages.

The research of the social profile of electronic money users in some Russian cities such as Astrakhan, Volgograd and Saratov was done on the basis of the questioning and interviewing the citizens.

The authors systematized and generalized the characteristics of the existing approaches to the organization of electronic payment and settlement systems - centralized and decentralized - to identify the risk levels of each of them. As a result, it allowed us to formulate the proposals on the improvement of the electronic money systems using the blockchain technology in centralized systems. We also characterized the requirements to cryptocurrencies as types of electronic money and forecast the number and the amount of transactions processed with electronic money.
\end{abstract}

Keywords - electronic money, payment system, cryptocurrency, blockchain technology

\section{INTRODUCTION}

The specific features and characteristics of electronic money and its large-scale development and expansion in daily life of societies attracted attention of both potential users and controlling and regulating authorities.

Current high interest to the improvement of the procedures of its circulation can be explained by the successful functioning of private electronic money and cryptocurrency systems, the impact of the global economic crisis and cyberthreats in the financial sphere.

Nowadays, both economic entities and whole countries have the need for the legitimate use of the decentralized approach to the organization of electronic payment systems on the basis of the blockchain technology as they lack the main shortcomings of centralized systems in terms of their secure processing. Thus, the problems of the development and spread of the electronic money use and the adaptation of the cryprocurrencies in the payment system are of primary importance.

\section{MATERIALS AND METHODOLOGY}

Cryptocurrencies, the blockchain technology as well as the organization and functioning of decentralized cryptosystems were investigated by S. Atey, A.E. Robbeck (2014), E. Seytim Ayganym (2014), etc.

Nowadays, there are three conceptual approaches to the definition of electronic money in economics: a payment definition, the definition of money as a non-monetary financial product, and a monetary definition. The first approach is supported by S. Singh (2004) and C. Freedman (1999), the second is recognized in the documents of the Bank for International Settlements (2010), the European Parliament (2009), the European Central Bank (1998, 2008, 2015) while the third approach is accepted by a number of the contemporary economists.

The payment and monetary definitions of the essence of electronic money cannot be considered as satisfactory while its definition as a non-monetary financial product is believed to be the most appropriate. According to it, electronic money is characterized by a number of specific features and characteristics, such as the immediate transfer and disclosure on electronic accounts (digital wallets); fast authentication; the convenience of transactions; the absence of territorial and / or time limitations of movement; low fees; high divisibility.

At the current stage of the IT development, electronic money is a full-fledged means of non-cash payment, a prepaid financial product, not linked to the personalized bank account, allowing its owner to demand the fulfilment of monetary obligations from the electronic money system operator through the refund of the prepaid money (used as a coverage), which records are maintained without personal bank accounts.

To disclose information on the availability of money in the system that provides the possibility to transfer it among users, it is necessary to have an electronic account. We consider the 
concept of 'a means of non-cash payment' to be more justified than the concept of 'a type of non-cash payment' as the former functions as an account document while the latter defines the order of flow of documents and the algorithm of the money transfer from a sender to a receiver.

The official recognition of electronic money as a legitimate means of payment, in our opinion, neutralizes its prepaid nature as, after being officially recognized, it will be non-cash money the storage and the transfer of which will be possible both through the existing and the new information technologies. An electronic account will be equal to the bank account, which will enable the organizations to transfer electronic money in the fixed form among them as well as will define its commonly-accepted form on the whole territory of the country.

The study of the electronic money evolution within the period between 1850 and 2016 revealed 74 phases of the implementation of technical and technological know-hows which can be combined into 8 stages:

- cable money transfers (since 1850);

- cards issued by non-banking organizations and used as a client identification which entitles him to receive services (since 1914);

- cards issued by banks (since 1951);

- conversion of financial information into the electronic form (since 1951);

- magnetic strip cards (since 1968);

- smart-cards with built-in chips (since 1974);

- distance banking services (since 1984);

- electronic money (since 1990).

The genesis of the electronic money has a technological profile, which means that its appearance and development in the currently existing form was induced, on the one hand, by the rapidly growing need for faster and larger payments and settlements, on the other hand, by the technological advances. Taking into account the conclusion, we can state that the further improvement and development of the electronic money technology will be enhanced by the innovations in the sphere of the information technologies and telecommunications while its financial content will be defined by the legal aspects delegating the functions in payments and settlements to new technologies.

It should be emphasized that the problem of keeping the record of the coverage of electronic money as the electronic money that is not covered in full increase money supply not covered by the corresponding amount of goods, which may lead to higher inflation rates. However, electronic money in its current status is not included in the money supply. Besides, it is not defined if the balance of an account that keeps the coverage of electronic money is included in the money supply.

In our opinion, the money which is covered by the legitimate money and is able to be used in the settlements and payments should be included in the money supply (aggregate M1) regardless of its form. The following should be taken into consideration:

- if electronic money coverage is reserved only partially, the spread between the amount of electronic money and the account balance of the deposited money that are used as a coverage of electronic money should be included in the money supply;

- if electronic money coverage is fully reserved, the account balance of the deposited money that is used as a coverage should not be included in the money supply.

Considering risks as an integral part of centralized and decentralized systems of electronic money, one should mention that decentralized cryptosystems function officially and are recognized by law and their functioning is effectively controlled. Therefore, they are less risky compared with the centralized systems; in fact, the only risk assumed in such system is client errors. Nevertheless, functional and technological characteristics of the decentralized systems are worse than those of the centralized: the absence of possibility to block accounts or recover credentials, the absence of control over the clients' transactions and flexible terms of service rendering as well as low velocity of transactions.

Low riskiness, high degree of reliability and security of transactions in decentralized cryptocurrency systems are provided by the blockchain technology they are based on. However, due to the peculiarities of their functioning, the currently existing cryptocurrencies can not be used to design a legitimate decentralized cryptocurrency system. Thus, to use the blockchain technology in the payment system, it is necessary to eliminate the drawbacks of the decentralized approach to the system organization, to arrange the cryptosystem management, the control over and the regulation of its functioning as well as to introduce the requirement of the obligatory coverage of the cryptocurrency.

Under current economic and political conditions the popularity of electronic money increases every year. According to the statistics of the European Central Bank (2016), an increase in the number of transactions with electronic money and their share in the total amount of noncash settlements was registered on the territory of the European Union. In the countries-members of the Eurasian Economic Community, the level of the development and the use of electronic money is relatively low despite the existence of the legislation and they are not recognized as an independent settlement instrument.

\section{RESULTS AND DISCUSSION}

Taking into account the undertaken analysis of the structured information, we can identify the general advantages and disadvantages of centralized and decentralized electronic payment and settlement systems.

So, the main advantages of the centralized systems are: 1) personal data security; 2) electronic money coverage by the legitimate money or precious metals; 3) rigorous exchange rate of electronic and traditional money; 4) official representative responsible for the system functioning and regulation; 5) the existence of the centralized authority responsible for dispute resolutions and consideration of claims; 6) available account blocking and rejection to make suspicious transfers. 
The typical disadvantages of centralized electronic money systems are as follows: 1) the centralized system management and data storage; 2) low transparency of the system performance (no access to statistics, the complexity of the data check); 3) no public access to the statistics on electronic money (on each electronic money system, in particular); 4) impossible real-time monitoring and audit of the electronic money operators' activities by the Central Bank; 5) possible uncovered emission of electronic money.

The advantages of the decentralized cryptosystems are: 1) their independence of the attacks or certain server failures due to the territorial distribution of the network; 2) the transparency of all financial operations; 3) the availability of the source code of the software, which enables the user to modify the system; 4) high level of cryptoresistability enough for the safe storage of personal data and financial information; 5) immediate disclosure of the amount of the transfer in the sender's and receiver's digital wallets; however, the confirmation of the transaction takes some time before the receiver will be able to use the money.

The weaknesses of decentralized cryptosystems are: 1) the absence of the centralized authority responsible for the control over the system functioning; 2) impossible resolutions of claims due to the absence of the official representative of the cryptosystem; 3 ) the absence of the guaranteed coverage of a unit in the system; high volatility of the cryptosystem units which depends on its demand; 4) possible implementation of the «51 \%» and «dust» attacks; 5) impossible account blocking and rejection of suspicious transfers, i.e. management of the account status and the transfer process; 6) impossible recovery of the private key of the digital wallet and cancellation of transfer; 7) low speed of transaction confirmation (about 1 hour); 8) impossible change of the private key of the digital wallet (the storage of the cryptocurrency in the compromised digital wallet becomes insecure).

The authors carried out the empirical research of electronic money use as a legal tool of non-cash settlement in the Russian cities such as Astrakhan, Volgograd and Saratov.

Four groups of respondents participated in the interview. The first group included respondents aged under 18 (780 people); the second group participants were aged between 18 and 25 (708 people); people aged 26 - 40 formed the third group (900 people); the fourth group included citizens aged 40 and older (708 people). $51.6 \%$ of all the respondents were female, $48.4 \%$ were male.

According to the data received, $36.7 \%$ of the respondents are aware of the prepaid financial product "electronic money" and do not confuse it with concept of the "online banking services" and "a bank card". 667 people have their electronic account, which is $21.5 \%$ of all the respondents.

The majority of them are people at the age between 26 and 40 who are employed and run their own business (59.4\%), students and temporarily unemployed (33.6\%); the smallest group includes retired people $(7 \%)$. It is worth mentioning that $74.6 \%$ of all users of electronic money are male.
The respondents who do not have any electronic account explained it by the superficial knowledge of the new payment tool; lack of skills in the use of computers and software including the Internet; no need for online settlements; absence of the obvious advantages of electronic money over online banking services and bank cards; reluctance to adopt new technology and means of settlement; fear of risks connected with the use of electronic money.

The majority of electronic accounts $(49.8 \%)$ are opened with the simplified identification, $40.2 \%$ are opened anonymously and only $10.0 \%$ are opened with full identification in the office of the electronic money system representative.

The fact that the majority of the users open their electronic accounts with full or simplified identification means that the anonymity of settlements is not the main reason to prefer electronic money to other settlement and payment instruments. The questioning showed that a half of electronic money system users carry out transactions not more often than once a month, $38 \%$ of the respondents - 2-9 times a month, $11.8 \%$ more often than 10 times a month.

The prevailing areas of the settlements with electronic money are payments for mobile communication (543 people), the Internet (482 people); television (436 people); wire telephone (302 people); goods bought online (298 people); online services (186 people).

To get the access to the electronic money systems, the users mostly use computers $(48.6 \%)$ and mobile devices $(42.3$ $\%)$. The respondents usually use electronic money as a settlement instrument with the following periods of time: 16:00 - 19:59 (41.7\%) and 20:00 - 23:59 (31.9\%).

The respondents - electronic money users mention its following advantages: its high transaction velocity (39.1\%); absence of territorial (22.2\%) and time (19.8) limitations; low fees $(16.4 \%)$, availability of anonymous settlements $(2.5 \%)$.

As disadvantages, the respondents mentioned low security of electronic money (52.6\%), failures of hardware and the Internet $(38.3 \%)$, the refusal of contractors to accept electronic money a means of settlement $(5.2 \%)$, inconvenient interface and the need for extra knowledge (3.9\%).

The data received provide the evidence that currently electronic money are at the dawn of its formation. This fact is supported by the annual increase in the number and volume of the transactions with the use of electronic money.

The future development of electronic money and higher efficiency of the payment systems will be the legitimation of the financial settlement instruments based on the blockchain technology.

The sufficient benefits of the use of the cryptocurrency recognized by law allow us to assume the substantial users' demand for settlement transactions, which may lead to the growing profitability of the system exploitation. This assumption is justified by the forecast of the dynamics of the number of users in the legitimate cryptocurrency system based on the of the Gompertz and Pearl-Reed functions growth curves (Figure 1). 


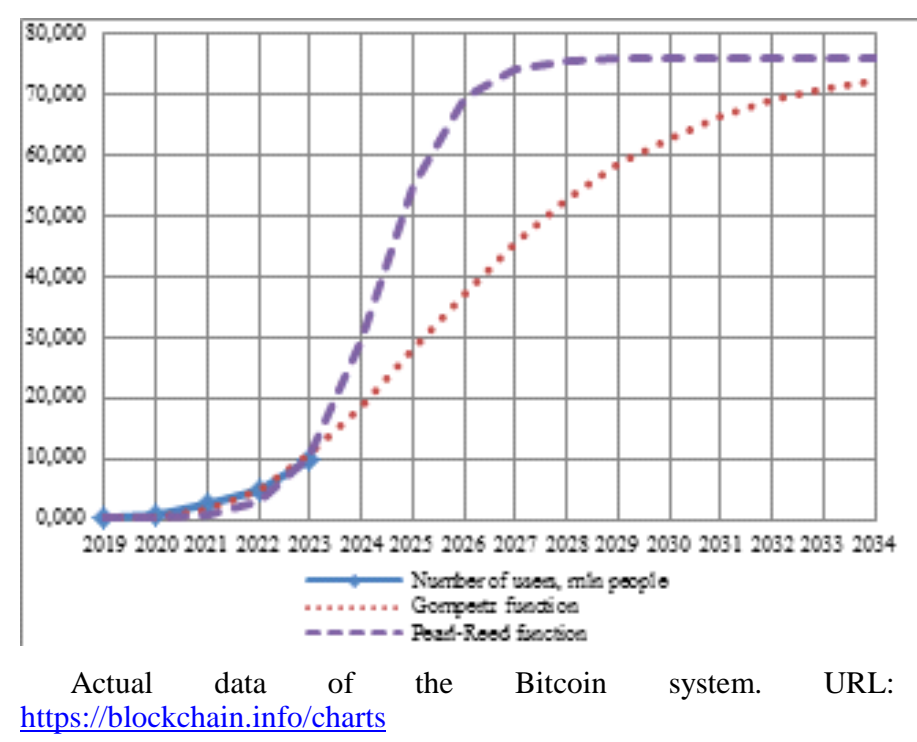

Fig. 1. The forecast of the dynamics of the number of users in the modeled cryptocurrency system based on the Gompertz and Pearl-Reed functions and actual data of the Bitcoin system, mln people.

The introduction of the cryptocurrency in the payment system is the integral part of the Internet economy development and the trend in the economic development. In addition to the economic impact of the cryptosystem use, the positive social effect will be achieved, which means higher degree of transparency and security of the payment and settlement transactions as well as the lower cost of cash circulation.

High-tech innovations in the sphere of settlement and payment including electronic money play a key role in the increase in the efficiency and competitiveness of the payment systems.

As the sphere of electronic money is developing yet, a number of measures should be undertaken to enhance its development and wide-spread use, such as the improvements in the regulating mechanism in the sphere of electronic money; the introduction of decentralized cryptocurrency systems (the blockchain technology) in the payment system; the use of the blockchain technology and cryptographic security tools in centralized systems.

To use a cryptocurrency, it is necessary to develop the legal regulatory mechanisms and technological system modifications that meet the requirements of the legislation as well as to create new decentralized infrastructure in which a particular organization will be responsible for the control and the functioning of the system. It will enable the users to send claims to the official representative in case of disputes (Table 1).
TABLE I. The comparison of the approaches to the creation of the decentralized infrastructure of electronic money

\begin{tabular}{|c|c|c|c|c|}
\hline \multirow{2}{*}{ Parameters } & \multicolumn{2}{|c|}{ Approach 1} & \multicolumn{2}{|c|}{ Approach 2} \\
\hline & Model 1 & Model 2 & Model 1 & Model 2 \\
\hline Miner (emitter) & $\begin{array}{c}\text { The } \\
\text { Central } \\
\text { Bank }\end{array}$ & $\begin{array}{c}\text { The } \\
\text { Central } \\
\text { Bank }\end{array}$ & $\begin{array}{l}\text { Financial } \\
\text { organizati } \\
\text { ons }\end{array}$ & $\begin{array}{c}\text { Financial } \\
\text { organizations }\end{array}$ \\
\hline System creator & $\begin{array}{c}\text { The } \\
\text { Central } \\
\text { Bank / } \\
\text { Financial } \\
\text { organizati } \\
\text { ons }\end{array}$ & $\begin{array}{c}\text { The } \\
\text { Central } \\
\text { Bank }\end{array}$ & $\begin{array}{c}\text { The } \\
\text { Central } \\
\text { Bank }\end{array}$ & $\begin{array}{c}\text { Financial } \\
\text { organizations }\end{array}$ \\
\hline $\begin{array}{c}\text { The } \\
\text { organization } \\
\text { establishing the } \\
\text { conditions and } \\
\text { rules of } \\
\text { settlements in } \\
\text { cryptocurrency }\end{array}$ & $\begin{array}{c}\text { The } \\
\text { Central } \\
\text { Bank / } \\
\text { Financial } \\
\text { organizati } \\
\text { ons }\end{array}$ & $\begin{array}{c}\text { The } \\
\text { Central } \\
\text { Bank }\end{array}$ & $\begin{array}{c}\text { The } \\
\text { Central } \\
\text { Bank }\end{array}$ & $\begin{array}{c}\text { Financial } \\
\text { organizations }\end{array}$ \\
\hline $\begin{array}{l}\text { Depositing of } \\
\text { legal money } \\
\text { (cryprocurrency } \\
\text { coverage) }\end{array}$ & \multicolumn{4}{|c|}{ The Central Bank } \\
\hline $\begin{array}{c}\text { Issue of } \\
\text { licenses, control } \\
\text { and regulation }\end{array}$ & \multicolumn{4}{|c|}{ The Central Bank } \\
\hline $\begin{array}{l}\text { Registration of } \\
\text { final users }\end{array}$ & \multicolumn{4}{|c|}{ Financial organizations } \\
\hline Cryptocurrency & \begin{tabular}{|c|} 
Private / \\
Autonomous
\end{tabular} & Common & Common & $\begin{array}{c}\text { Private / } \\
\text { Autonomous }\end{array}$ \\
\hline
\end{tabular}

Thus, it is reasonable to integrate the financial and settlement instruments and the blockchain technology in the payment system for its modernization, the wider use of electronic money as well as for the higher efficiency and security of the settlements with the use of electronic money.

\section{CONCLUSION}

1. The incentive for the appearance and the development of electronic money in the current form was, on the one hand, the rapidly increasing need for the faster and larger scale of payments and settlements, on the other hand, the technological advances. So, the further improvements in the electronic money technology will induced by the innovations in IT and telecommunications while the financial content will be based on the legal aspects delegating payment and settlement functions to new technologies.

2. The development of the technologies and the expansion of the electronic money use are aimed at increasing their popularity, reliability and economic value. The cryptocurrency officially recognized in the legislation as well as the changes in the current legislation regulating settlements with the use of electronic money will result in clear understanding of the functioning of electronic money systems and cryptosystems and will provide the basis for the efficient regulation of their use.

3. The official recognition of electronic money as a legal means of payment will certainly neutralize its prepaid nature: after being given the official status, it will be non-cash money which storage and transfer will be possible both with the 
existing and new technologies of information storage, processing and transmission. The new vision of the electronic money nature will contribute to the deeper understanding of the practical use of its technology and will concentrate the legislators' and the creators' efforts in one way.

4. Fast and convenient settlements with the electronic money disregarding the existence or the absence of its coverage reservation influence the velocity of money supply circulation. The electronic money with partial reservation increase the amount of money supply which is not covered by the corresponding amount of goods. The latter may cause higher inflation rates.

5. The empirical research conducted in different regions of Russia provided social profile of an electronic money user in Russia: a male person aged between 26 and 40, employed or running his own business. The majority of settlements are processed from 16:00 to 23:59, and the average amount of all transactions is up to 3,000 rub.

6. The main trends of the electronic money development and the improvements in the payment system may be the modernization of the regulating mechanisms in the sphere of electronic money and the introduction of decentralized cryptocurrency systems. As for centralized electronic money systems, their main development trends might be the following: the application of the encryption-based safeguards to confirm the circulation of electronic money; the introduction of the common transaction register based on the blockchain technology to disclose the circulation of electronic money; interface implementation for the interoperability of centralized and decentralized cryptocurrency systems.

7. The cryptocurrency officially recognized in the legislation as well as the changes in the current legislation regulating settlements with the use of electronic money will result in clear understanding of the functioning of the electronic money systems and cryptosystems and will provide the basis for the efficient regulation of their use. The abovementioned factor will provide the basis for the corresponding statistics that will contribute to the comprehensive idea of the role and place of electronic money in the payment system.

\section{References}

[1] A.E. Robbeck, "Bitcoin as a Phenomenon in World Economy". Bulletin of M.K. Ammosov North-East Federal University. 2014. Volume 11. No. 6. pp. 114-118.

[2] E.Seytim Ayganym, "Use of Cryptocurrencies as Alternative Solution in World Currency System". Problem of Economy. 2014. No2. P. 50-55.

[3] S.Singh, "Impersonalisation of electronic money: implications for bank marketing". International Journal of Bank Marketing. 2004. Vol. 22. No7. pp. 504-521

[4] C.Freedman, "Monetary Policy Implementation: Past, Present and Future-Will Electronic Money Lead to the Eventual Demise of Central Banking?”. International Finance. 2000. Vol. 3. №2. pp. 211-227.

[5] Directive 2009/110/EC of the European Parlament and of the Council of 16 September 2009 amending Directives 2005/60/EC and 2006/48/EC and repealing Directive 2000/46/EC.

[6] Survey of electronic money developments. Report by the Committee on Payment and Settlement Systems of the central banks of the Group of Ten countries // Committee on Payment and Settlement Systems. Bank for International Settlements. URL http://www.bis.org/cpmi/publ/d48.pdf

[7] European Central Bank. Electronic money institutions current trends, regulatory issues and future prospects. Legal Working Paper Series. European Central Bank. 2008. №7. 48 p.

[8] European Central Bank. Report on electronic money. Frankfurt on Main, 2015. 47 p.

[9] Bank for international settlements. CPMI - BIS - Red Book: CPMI countries. URL http://www.bis.org/list/cpmi/sac_1/tid_57/index.htm

[10] Bitcoin cyberextortionists are blackmailing banks, corporations. URL http://arstechnica.com/business/2015/09/uk-banks-corporations-arebeing-blackmailed-by-bitcoin-cyberextortionists/

[11] Bulletin of National bank. URL: http://www.nbkr.kg/index1.jsp?item=137\&lang=RUS

[12] Payment and settlements system. Statistics and reporting. URL: https://www.cba.am/am/sitepages/psstatisticaldatareports.aspx

[13] Statistics of payment systems. URL: http://www.nationalbank.kz/?docid=275\&switch

[14] Monetary aggregates. URL http://www.ecb.europa.eu/stats/money/ aggregates/aggr/html/index.en.html

[15] Payments Statistics (full report). URL http://sdw.ecb.europa.eu/reports.do? node=1000004051

[16] M. Young, The Technical Writer's Handbook. Mill Valley, CA: University Science, 1989. 